Instructions for authors, subscriptions and further details:

http://rasp.hipatiapress.com

\title{
El Movimiento-tiempo Real y el Movimiento-tiempo Animado
}

\section{Alicia Fernández ${ }^{1}$}

1) Facultad de Ciencias de la Educación. Universidad de Granada. España

Date of publication: June $3^{\text {rd }}, 2018$

Edition period: February 2018-June 2018

To cite this article: Fernández, A. (2018). El Movimiento-tiempo Real y el Movimiento-tiempo Animado. Barcelona, Research, Art, Creation, 6(2), 212227. doi: $10.17583 /$ brac.2018.2350

To link this article: http://dx.doi.org/10.17583/brac.2018.2350

\section{PLEASE SCROLL DOWN FOR ARTICLE}

The terms and conditions of use are related to the Open Journal System and to Creative Commons Attribution License (CC-BY). 


\title{
Real motion-time and animated motion-time
}

\author{
Alicia Fernández \\ Faculty of Education Sciences. University of Granada. Spain \\ (Received: 17 October 2016; Accepted: 9 April 2018; Published: 3 June \\ 2018)
}

\section{Abstract}

Animated movement has its own peculiarities, which differentiates itself from real movement. Being animation and performing arts two kinds of artistic expressions that are based on the creation of a work from the movement, we wonder whether the differences between these two kinds of movement propitiate that animated movement is not really a movement as such. This hypothesis is given by peculiarities in the creation of animated movement, as it could be that this would be created from static images or the necessity of being reproduced in audiovisual format. Thus, we analyze characteristics of movement in performing arts and animation through ideas about movement and time of certain thinkers to reach a conclusion on the question proposed.

Keywords: Animation, performing arts, motion, time, philosophy 
BRAC - Barcelona Research Art Creation Vol. 6 No. 2 June 2018 pp. $212-227$

\title{
El Movimiento-tiempo Real y el Movimiento-tiempo Animado
}

\author{
Alicia Fernández
}

Facultad de Ciencias de la Educación. Universidad de Granada. España

(Recivido: 17 octobre 2016; Aceptado: 9 abril 2018; Publicado: 3 junio 2018)

\section{Resumen}

El movimiento animado tiene sus propias peculiaridades, lo que le diferencia del movimiento real. Siendo la animación y las artes escénicas dos tipos de manifestaciones artísticas que se basan en la creación de una obra a partir del movimiento, nos planteamos si las diferencias entre los dos tipos de movimiento propician que el movimiento animado no sea realmente un movimiento como tal. Esta hipótesis viene dada por peculiaridades en la creación del movimiento en animación, como podría ser que este sea creado a partir de imágenes estáticas o la necesidad de ser reproducido en formato audiovisual. De este modo analizaremos las características del movimiento en artes escénicas y en animación, pasando por las ideas sobre el movimiento y tiempo de ciertos pensadores, para llegar a una conclusión sobre la cuestión planteada.

Palabras clave: animación, artes escénicas, movimiento, tiempo, filosofía.

2018 Hipatia Press

ISSN: 2014-8992

DOI: $10.4471 /$ brac. 2018.2350

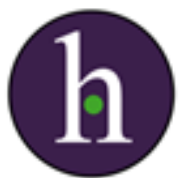




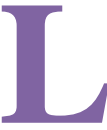

a animación está ligada al resto de las artes. Artes como pintura, dibujo, cómic, pasando por la música, el teatro y la literatura. La animación posee elementos ya existentes en el resto de las artes. En este artículo, nos centraremos en las relaciones entre las artes escénicas (teatro, danza, performance y happening) y la animación, planteándonos la pregunta ¿Es realmente la animación un arte móvil? Esta pregunta se inspira en la diferencia entre el movimiento real natural y el movimiento artificial de la animación, creado a partir de fotogramas, que a su vez son imágenes estáticas. La hipótesis que motiva este artículo se pregunta por la realidad del movimiento que proporciona la animación como movimiento en sí mismo, es decir, hasta qué punto es real un movimiento que no es igual que el movimiento real y que está conformado por imágenes estáticas ¿Es acaso la asignación del concepto movimiento al movimiento animado una equivocación o por el contrario el movimiento de la animación puede llegar, como movimiento que es, más allá que el movimiento real de las artes escénicas?

Comenzamos analizando los puntos comunes y confrontados entre animación y artes escénicas, desde un enfoque filosófico (planteando preguntas sobre el concepto movimiento y el concepto tiempo), para poder llegar a una conclusión desde el análisis previo. Aun siendo el movimiento animado un movimiento que se basa en la imitación del movimiento real, ambos comparten similitudes como la duración, el desarrollo o el cambio local, sin embargo, también encuentran puntos encontrados. Estudiaremos autores y filósofos que investigaron sobre el movimiento y el tiempo, cuyas teorías están relacionadas con el movimiento en las artes audiovisuales. Autores como Deleuze, que investigaron en qué medida se pensaba en el movimiento como poses consecutivas, basado en la división de instantes, lo cual fusionaría un aspecto importante del movimiento animado con el real. Otro carácter que estudiaremos, y que une movimiento real y animado, es la forma en el que recibimos el movimiento. Es este procesamiento abstracto del cerebro el que crea, según Bergson, los cortes en la realidad, que de otra manera no podrían existir. Es por ello que, para este autor, el movimiento animado solo es una ilusión de movimiento. Contra esta teoría de Bergson, Deleuze utilizará su concepto corte móvil. Entre otros autores, estudiaremos la semejanza entre la imagen-movimiento e imagen-tiempo de Deleuze y los 
conceptos perpetuo y eterno de Platón, relacionados con la percepción humana, necesaria para apreciar, como hemos mencionado, cualquier clase de movimiento. Siguiendo con la investigación, iniciamos un tercer punto en el que proponemos semejanzas y diferencias entre el movimiento en las artes escénicas y la animación; reflexionaremos sobre la irreproducibilidad del movimiento real; la necesidad de coreografía o movimiento interpretado en las artes escénicas (algo que también es necesario en animación); el movimiento real dentro de la animación; los soportes; la combinación de técnicas artísticas y los métodos de reproducción.

Con toda la información recabada, analizaremos en este artículo las distintas formas de pensar el movimiento real y el movimiento animado de distintos autores y autoras, para llegar a una conclusión sobre qué aporta el movimiento animado y, lo más importante, si podemos considerar este movimiento de la animación tan válido como el real o no.

La metodología utilizada para esta investigación se basa, primeramente, en la obtención de datos y teorías valiosas para el estudio de movimiento real y el movimiento animado, de autores y autoras que se preguntaron sobre el movimiento y el tiempo, y cuyos conceptos están relacionados con el movimiento en animación y en artes escénicas. Seguidamente, recapacitaremos sobre distintos puntos en común y en contra en el movimiento real de las artes escénicas, y el movimiento de la animación. Con todo ello crearemos unas conclusiones que contestarán a las preguntas planteadas en la hipótesis.

\section{Pensamiento sobre Movimiento y Tiempo}

Es obvio que hay diferencias entre el movimiento generado por la acción en la realidad y cómo se crea el movimiento en animación. El movimiento real es producido por objetos y personas reales, en un tiempo real, mientras que el movimiento animado es un proceso artificial que en numerosas ocasiones pretende (sobre todo en animación figurativa), simular el movimiento real. Comenzaremos por exponer las tres formas de movimiento que la animación necesita para poder ser generada y percibida, según la catedrática Carmen Lloret. 
En la animación, la expresión móvil que el espectador percibe se ocasiona por la conjunción de tres modos de movimiento: la representación virtual del movimiento (contenida en cada una de las imágenes), y la presentación del movimiento, este último en sus modos: movimiento óptico (basado en la ilusión óptica, denominada Persistencia de la visión), y el movimiento real que la tecnología nos proporciona. Sin la simbiosis de todos ellos no sería posible su realización. (Lloret, 2016, p. 299)

El movimiento animado es la conjunción de los tres tipos de movimiento explicados por la catedrática Lloret. Por otro lado, las artes escénicas son espaciales y temporales, con un principio, un fin y un desarrollo de la obra donde se escenifica la narración (García, 1991, p. 128) de la misma manera que ocurre en animación. El punto en común entre movimiento real y animado reside en el cambio local, si una imagen no posee ningún movimiento en la pantalla estaremos ante un fotograma estático prolongado en la línea de tiempo durante más de un solo fotograma, no ante animación. Esta visión tiene mucho que ver con las técnicas de animación, en las que el tiempo, el espacio y el progreso del movimiento están asociados a través de la percepción, ya que, según Deleuze, el plano crea un conjunto espaciotemporal en el que actúa la imagen-movimiento (Deleuze, 1994, p. 105). En el caso del movimiento real, aunque sea imperceptible al ojo humano, siempre existe movimiento. El medio por el que percibimos el movimiento es exactamente el mismo en animación y acción real, a través de la visión, la cual puede apreciar un número limitado de movimientos: ya sea movimiento animado o real, solo podrá captar formas borrosas si es demasiado acelerado. El problema surge con la fragmentación de instantes, que es la clave de separación entre movimiento animado y real. Según autores como Descartes solo se puede dar la existencia en presente a través de la Creación Continuada, teoría formulada por Descartes (Corazón, 1996) por la que todo lo existente se regenera a cada momento para poder seguir existiendo, haciendo referencia a la división del tiempo y el movimiento en instantes (Corazón, 1996, p. 76). Esta afirmación traerá consigo un nexo en común entre el movimiento real y animado: ambos están seccionados en poses por los instantes (en la realidad) y por fotogramas (en animación). Según esta teoría, el tiempo real se dividirá en secciones como ocurre con el tiempo en 
animación. La diferencia residirá en la imposibilidad de percibir saltos entre imágenes en el movimiento real y la posibilidad de poder diferenciarlos en animación. Contrarios a Descartes, existen autores que piensan que el tiempo no puede dividirse en instantes, sino que es la mente humana la que crea las divisiones, como ocurre en el caso de Merleau-Ponty (1997, p. 420). Si se da por válida esta segunda teoría y el cerebro es el encargado de dividir la realidad en presente, pasado y futuro, comprendiendo el presente como instantes, podemos encontrar otro nexo en común entre el movimiento animado y el real: el proceso mental. Si lo que nuestro cerebro percibe es movimiento ¿Qué problema hay en que no sea un movimiento real, es decir, natural, sino un movimiento artificial, creado por otros tipos de componentes? La percepción no nos engaña, de una manera u otra, lo que estamos percibiendo al visualizar animación es movimiento. El cerebro actúa como unión, tanto para la información que proviene del movimiento real, como del animado, y las procesa de la misma manera, convirtiéndolas en recuerdos. Las imágenes de movimiento real, que una vez fueron tangibles, dejarán de serlo dentro de la mente. Las imágenes reproducidas en una animación, que no son tangibles (pues están conformadas por luz), tampoco lo serán cuando pasen a formar parte de nuestra memoria. La mente almacena estos recuerdos, utilizando sus propios filtros y sistemas de montaje, a la manera de una producción audiovisual. Como bien expresa Bergson.

Vosotros no podréis reconstruir el movimiento con posiciones en el espacio o con instantes en el tiempo, es decir, como <<cortes>> inmóviles... Sólo cumplís esa reconstrucción uniendo a las posiciones o a los instantes la idea abstracta de una sucesión. (Deleuze, 2011, p. 13)

Un medio para engañar a nuestra mente y a nuestra visión, mostrándole el movimiento real fragmentado, podría ser a través de cortes de luz parpadeantes (como luces estroboscópicas). Nuestro cerebro no podrá percibir la continuidad del movimiento, sino cortes aislados con relación secuencial entre ellos. Por su parte, la luz estroboscópica es necesaria para percibir los fotogramas aislados de un tipo de animación cuya reproducción no está ligada al soporte audiovisual: los zootropos 3D, un ejemplo sería el 
zootropo situado en el Ghibli Museum de Mitaka. Sin la luz estroboscópica, al no ser un movimiento real el que estamos presenciando (sino un movimiento animado de figuras en tres dimensiones que crean fotogramas aislados) si se acciona el mecanismo del zootropo, no podremos apreciar la sucesión en la secuencia de movimientos, solo viendo una ráfaga borrosa. Sin embargo, que nuestro cerebro perciba el movimiento de una manera especial por el efecto de estos parpadeos de luz, no quiere decir que el movimiento no se siga comportando exactamente de la misma manera.

Para Bergson, el cine solo es una ilusión de movimiento, ya que el cerebro es el encargado de reconstruir este movimiento irreal que nos ofrecen los fotogramas en reproducción. Sin embargo ¿No es el acto de reproducción audiovisual movimiento en sí mismo? Aunque lo que se nos está presentando sean fotogramas de imágenes inmóviles, el propio flujo del pasar continuo de una imagen a otra es un acto de movimiento real. Deleuze no cree que el movimiento audiovisual sea un mero pasar de imágenes estáticas, sino que introduce el concepto corte móvil, por el que, aunque las imágenes son fotogramas estáticos y existen cortes entre ellos, hay un movimiento constante creado por la correlación entre el movimiento de la imagen anterior y la posterior (Álvarez, 2011, p. 100). Tenemos claro entonces que existe movimiento, que no nos encontramos simplemente ante imágenes estáticas, sino que, al ser consecutivas, representan este movimiento, este corte móvil. Deleuze (1994, p. 26) además se plantea la imagen-tiempo desde dos puntos de vista: el primero es la comparación del tiempo con la imagen-movimiento, semejante al montaje de la animación, en el que el tiempo es definido por la duración de las acciones; y el segundo, la propia imagen-tiempo, cuyo tiempo es intrínseco, sin necesidad de comparación con espacio ni movimiento. Estos conceptos encontrados que aluden al tiempo se localizan ya en la filosofía de Platón. En su libro Timeo (Platón, 1999, p. 56) Platón reflexiona sobre la diferencia de los conceptos perpetuo y eterno: Eterno se corresponde con el tiempo en sí mismo, real, que no necesita de ningún otro elemento para existir; sin embargo, perpetuo se refiere al tiempo como transcurso del presente al pasado y al futuro, que necesita del movimiento para existir. De la única manera en la que, el concepto perpetuo para Platón, y la imagen-tiempo como imagenmovimiento para Deleuze, pueden existir es a través de la mente humana. De 
modo que, como dijimos, movimiento real y animado están sometidos a la percepción humana, englobados dentro del tiempo, sin embargo, no siendo necesarios para que el tiempo pueda existir. Deleuze usa el dibujo animado para explicar la imagen-movimiento, hablando del cambio entre imágenes consecutivas en el tiempo, afirma

Si pertenece plenamente al cine, es porque aquí el dibujo ya no constituye una pose o una figura acabada, sino la descripción de una figura que siempre está haciéndose y deshaciéndose, por el movimiento de líneas y puntos tomados en instantes cualesquiera de su trayecto. (Deleuze, 1994, p. 18)

Por otro lado, Bergson hace referencia al movimiento sustancial por el cual las transiciones que crean los movimientos se reflejan en las técnicas de animación que no imitan exactamente el movimiento real, sino que engendran un nuevo movimiento irreal. Ya no estamos ante un cambio local, sino ante una trasformación. Solo hablaríamos de cambio local en las técnicas de animación cuyos elementos en movimiento ya están prediseñados, no se redibujan o cambian a cada nuevo fotograma. Así explica Deleuze (1994)

Desde este momento, el movimiento, percibido o realizado, debe entenderse no ciertamente en el sentido de una forma inteligible (idea) que se actualizaría en la materia, sino en el de una forma sensible (Gestalt) que organiza el campo perceptivo en función de una conciencia intencional en situación. (p. 88)

\section{Similitudes y Diferencias entre Movimiento Animado y Movimiento Real}

Otras distinciones que podremos encontrar entre las formas de creación del movimiento animado y el movimiento real es la precisión de movimiento presente en ciertos tipos de animación donde los fotogramas se han realizado con la técnica clave a clave, que consiste en hacer primero dos fotogramas con poses clave para entender el movimiento, y una vez terminados estos, ir realizando los fotogramas intermedios y así sucesivamente. Una precisión 
imposible de conseguir en las artes escénicas. En animación, el movimiento queda prefijado en la preproducción y durante la producción, modificado al antojo de los creadores para conseguir los efectos deseados. En artes escénicas se puede pensar en actuar con movimientos prefijados, sin embargo, siempre existirá un componente de acción a tiempo real que creará mínimas diferencias entre actuación y actuación, la mayoría de ellas imperceptibles al ojo humano. Esto quiere decir que una actuación humana no puede repetirse exactamente igual que la anterior, moviendo los músculos con la misma intensidad, aceleración y posición espacial, que hace referencia a las diferencias de reproducción imprevisibles (Iniciarte, 2004, p. 54). Los únicos tipos de animación que podrían compararse con la irreproducibilidad del movimiento real serían aquellos donde esta fuese creada a tiempo real, un ejemplo sería la animación de líquidos. Esto quiere decir que estos tipos de animación creados a tiempo real, no se podrían volver a producir con los mismos movimientos exactos si se quisiera volver a crear la obra. Al igual que ocurriría en movimiento real, si esta animación es grabada y reproducida posteriormente, es lógico que encontraremos exactamente los mismos movimientos, sin embargo, serán imposibles de volver a obtener al recrear la obra de nuevo en la realidad. Cabe introducir en este punto a Jackson Pollock, quien utiliza el movimiento real y la actuación para generar obras pictóricas abstractas. Con sus obras consigue plasmar el proceso del movimiento, no solo representarlo. Al igual que la animación interactivagenerativa, las obras de Pollock y este tipo de animaciones se van generando gracias y según el movimiento humano, ya sea por el movimiento del espectador (agente externo sin el cual la obra podría seguir existiendo) en el caso de la animación interactiva, o por el del artista (agente interno creador necesario para la existencia de la obra) en el caso de Pollock (Rubio, 2010, p. 54). Por otra parte, el movimiento en animación obedece en muchos casos a una serie de pautas expresivas irreales (exageración, deformación, etc.). Aun cuando se intenta imitar lo más fielmente posible el movimiento real, este no se consigue al $100 \%$ a no ser que la técnica de animación utilizada sea Rotoscopio, por la que se calca directamente el fotograma desde la imagen real. No quiere esto decir que la técnica Rotoscopio cree un movimiento más verosímil que el resto, de hecho, el movimiento que obedece a las pautas expresivas irreales nombradas anteriormente crea una mayor sensación de movimiento real que el Rotoscopio, aunque el movimiento de este último provenga directamente de la realidad. Dependiendo del tipo de animación comprenderá movimientos más o menos 
cercanos al real, pudiendo ir desde animación figurativa de movimientos realistas, hasta la animación abstracta de creadores como Hans Richter o Viking Eggeling, cuyas representaciones y movimientos eran totalmente abstractos. Aún si la animación no pudiera considerarse un arte móvil debido a las características contrarias al movimiento real que residen en ella, esta es la única técnica conocida con la que podemos dotar de un cierto movimiento a objetos, elementos e imágenes inmóviles y, como explicamos anteriormente, posee sus propios principios y leyes expresivas, pudiendo ofrecer un movimiento más o menos real según el nivel de abstracción. De este modo, el movimiento animado, propio de la animación, es un movimiento artificial, pero también es un nuevo tipo de movimiento estudiado y coreografiado, al igual que en las artes escénicas. Este es un gran punto en común entre movimiento real y movimiento animado: en artes escénicas, los movimientos son interpretados y generalmente premeditados, incluso en la improvisación, los movimientos no son los mismos que se producirían en la vida real, fuera de la obra. Otra similitud entre animación y movimiento real es la necesidad de medición. En la vida real, medimos el movimiento a través del tiempo; en animación, la medida utilizada son los fotogramas. En la primera, no es imprescindible una medición exacta para que se dé un movimiento, sin embargo, en gran parte de las técnicas de animación sí, necesitaremos saber cuántos fotogramas tenemos que crear para conseguir un movimiento exacto. Como vemos, esta medición genera una similitud y a la vez una diferencia entre movimiento real y animado: por un lado, ambos poseen formas de medición, por otro, la espontaneidad del movimiento real hace que no sea para nada necesaria su medición, al contrario que en ciertos tipos de animación.

También podemos encontrar movimiento real dentro de la propia técnica de animación, como el que se da en la animación Stop Motion creada en entorno urbano. Un ejemplo es la obra Gerador \#1 (Leonor Pacheco y Bruno Caetano, 2015) (véase Imagen 1), realizada con dibujos sobre azulejos en un escenario real. Lo curioso que este tipo de obras aportan sobre animación y movimiento real es que este último puede apreciarse, sin embargo, nos lo muestra entrecortado debido al tiempo en que se ha tardado en borrar el fotograma anterior y dibujar el nuevo (en el caso de la obra citada) ¿Quiere esto decir que ese movimiento, que ahora se nos muestra entrecortado, no fue real? Al igual que explicábamos con el caso del movimiento real y el parpadeo producido por la luz estroboscópica, aunque nuestro cerebro no lo pueda percibir, el movimiento sigue comportándose de la misma manera. En 
Gerador \#1 hallamos unidos dos tipos de movimiento: real no actuado (nos muestra gente y coches pasando por la calle, ajenos a la grabación de la animación) y animado, en una sola obra. Del mismo modo podremos encontrar movimiento real actuado y animación en obras de cine de acción real en las que interactúan personajes animados y actores reales. Otra forma de encontrar tiempo real y animación ligados es a través de juguetes ópticos relacionados con la animación serían los zootropos, praxinoscopios, folioscopios, etc. En este caso, el movimiento real no ha sido captado en soporte audiovisual, sino que es necesario para la reproducción del objeto, siendo imprescindible la acción humana para su reproducción.

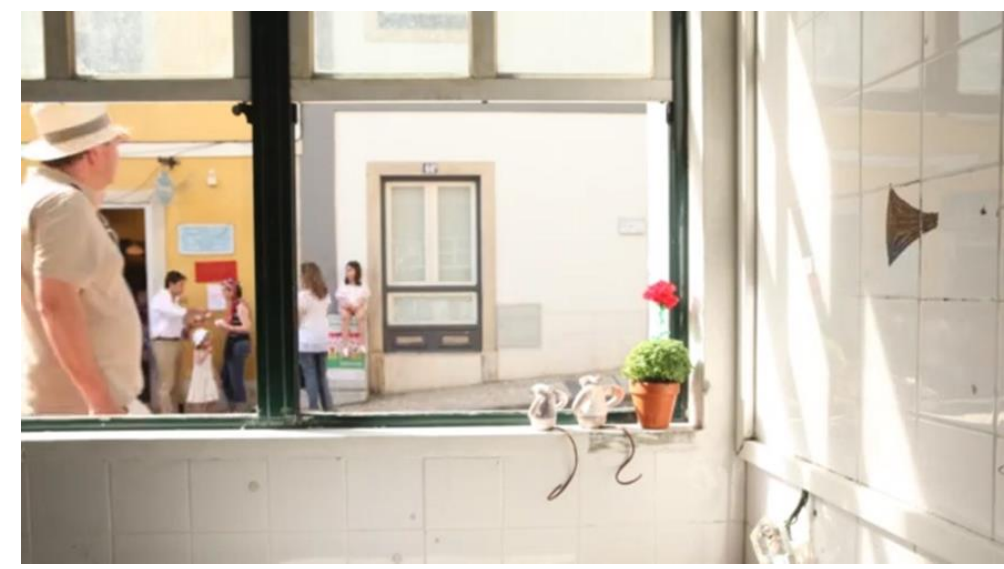

Imagen 1. Fotograma de la obra Gerador \#1 (2015) de Leonor Pacheco y Bruno Caetano. Recuperado de https://vimeo.com/130030384

El soporte es necesario para encontrar una obra física, ya que de otro modo solo tendríamos pensamientos no expuestos. Es imprescindible este viaje de la imagen al pasar de un formato a otro para poder conservar lo que un día fue una obra en tres dimensiones (García, 2006, p. 72). Encontramos que las artes escénicas, al igual que la animación, son artes que utilizan distintos tipos de técnicas artísticas, y no es de extrañar que, en algún momento, surgieran obras mixtas de artes escénicas y animación, como es el caso de la obra The Alchemi of Light (Dandypunk, 2013) (véase Imagen 2), donde existe interacción entre el personaje humano y el videomapping animado creado para esta actuación. Podemos volver a apreciar la unión entre 
movimiento real y óptico, fusionándose en la actuación a tiempo real y fundiéndose en un último formato audiovisual.

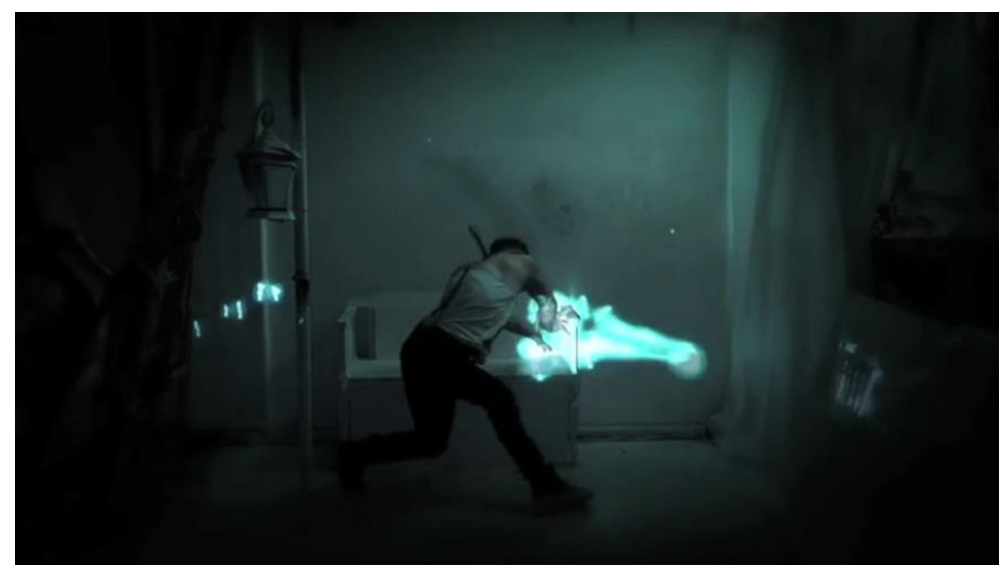

Imagen 2. Fotograma de la obra The Alchemy of Light de Dandypunk de 2013. Recuperado de https:// www.youtube.com/watch?v=UG2Xn_qDT0s

Somos conscientes de que, salvo en animación creada y expuesta en acción real como es la animación de líquidos creada en directo, la reproducción en animación difiere de la acción real. Aunque el público vea una animación a un tiempo de visionado real, lo que se reproduce, el contenido animado, no es creado a tiempo real. Algo que nos permite ver que esto no es así es la posibilidad de parar y rebobinar una animación, siendo imposible en acción real. Sin embargo, la mente trata y vuelve a unir el movimiento real y el animado: lo que el público está viendo en tiempo real, se procesa a la misma velocidad, es un tiempo de transición y movimiento imaginado cuyo paso es apreciable, que genera un cambio por efecto del desarrollo del movimiento, como explica Andy Joule "las elecciones que el animador toma sobre el movimiento afectan a la realidad con la que se percibe la película" (Joule, 2011, p. 60). Otro elemento de unión entre movimiento real y animado es la grabación de actos efímeros, que se puede dar en grabación a tiempo real o a través de Time Lapse. Para poder documentar las obras de artes escénicas es necesario el soporte audiovisual, de otro modo no podríamos ver la obra tal como fue, con movimiento. En el momento en que la obra de acción real es captada por las cámaras, pasa a formato audiovisual, adquiriendo las mismas 
características que la animación en soporte audiovisual ¿Significa entonces que, por no encontrarse en el mismo formato, no es movimiento? Como afirma Fernando García (2006)

Está claro que tanto la imagen mental como primera imagen o la reproducida por la última tecnología necesitan de un soporte de reconversión ya sea este las células cerebrales especialistas en el caso de la visión o la generación por ordenador en las pantallas de plasma de última generación. En ambos casos, sin esos soportes solo tenemos energía no captable por la percepción psicobiológica en el caso de la mente y, de igual modo, radiaciones en el caso de la tecnología digital. (p. 72)

Esta afirmación de Fernándo García nos vuelve a remitir a las teorías sobre la percepción y la visión como elementos que recogen cualquier tipo de movimiento, el cual será procesado, como dijimos anteriormente, de indistinta manera por el cerebro.

\section{Conclusiones}

Si volvemos sobre nuestros pasos, a la cuestión sobre si podemos considerar la animación un arte móvil, encontramos elementos en discordia entre el movimiento real de las obras de arte escénico y el movimiento animado: el movimiento real es natural mientras que el animado es artificial, en muchos casos simulando al movimiento real; existe una imposibilidad de apreciar saltos entre imágenes en el movimiento real, ocurriendo lo contrario en animación; la animación tiene sus propias leyes de movimiento; y finalmente la animación necesita de un soporte audiovisual, algo que no es imprescindible en artes escénicas. Por otro lado encontramos muchas similitudes entre movimiento real y animado: tanto el movimiento animado como el movimiento real de las artes escénicas encarnan movimientos de traslación (cambios locales) y transformación (cambios sustanciales), con separaciones entre poses (ya sea por efecto de los instantes o de los fotogramas); las obras tienen un principio y un fin marcados; son percibidos a través de la vista, procesados y almacenados por el cerebro, adquiriendo una misma codificación en nuestra mente y perteneciendo al mundo de los 
sentidos; son movimientos estudiados y premeditados, existiendo más exactitud de ejecución en animación. Por si no fueran pocas las similitudes, dentro de obras de animación podemos encontrar el movimiento real gracias al time lapse, a los juguetes ópticos y a otros tipos de animación como la interactiva, donde el movimiento humano crea el movimiento de la animación, como es el caso del Videomapping Interactivo expuesto en $\mathrm{Wu}$ Kingdom HelV Relic Museum (Tamschick y Acciona Producciones, 2013) (véase Imagen 3), creado por la empresa Tam.

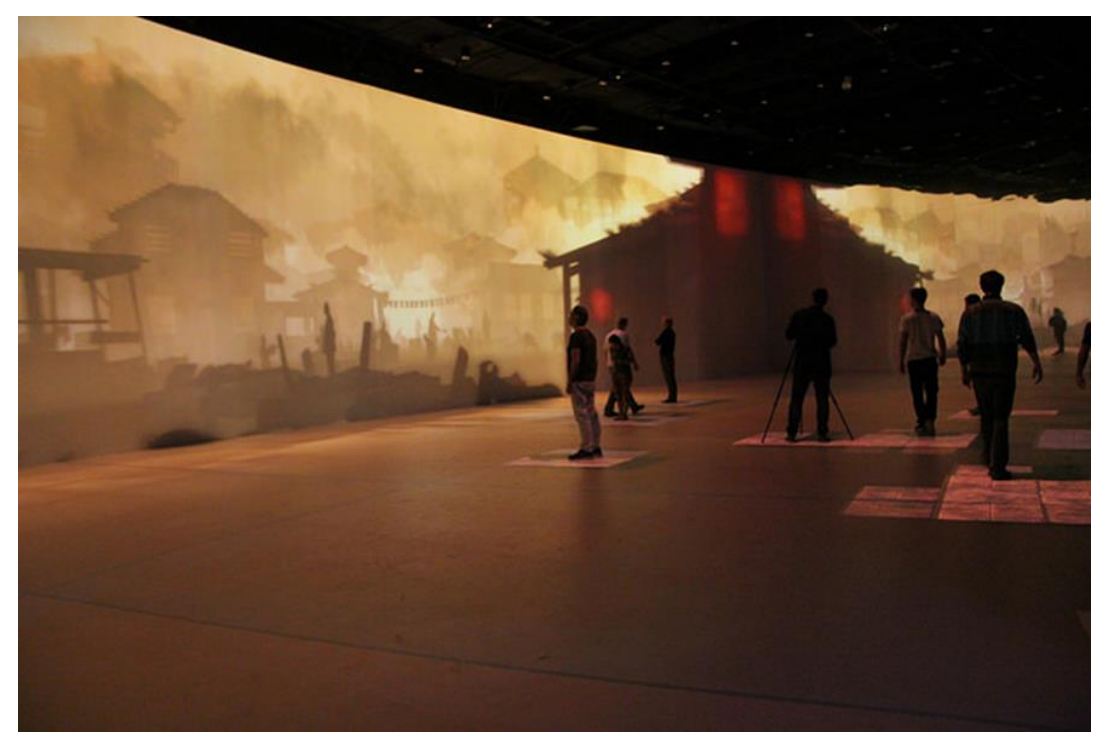

Imagen 3. Fotograma del videomapping interactivo expuesto en Wu Kingdom HelV Relic Museum (Tamschick y Acciona Producciones; 2013). Recuperado de https:// www.youtube.com/watch?v=PSoxGhVPTWs

En numerosas ocasiones, o, por la característica efímera de las artes escénicas, este es documentado en un soporte audiovisual, adquiriendo los procesos técnicos de reproducción de la animación. Asimismo, el movimiento de la animación permite su manipulación desde movimientos de imitación de la realidad hasta movimientos completamente irreales, 
fantásticos, que no se podrían pensar en el mundo real. Con tal número de diferencias, similitudes y peculiaridades, podemos determinar que el movimiento animado llega un paso más allá del movimiento real. El movimiento real es más limitado que el movimiento proporcionado por la animación. La animación es un arte móvil, por supuesto, pero, aunque en ocasiones adquiere el movimiento real, convirtiéndolo o no a soporte audiovisual, ha desarrollado una estética y una técnica propia, absorbiendo el movimiento real y evolucionándolo. El movimiento animado es una evolución del movimiento real, creado por el ser humano.

\section{Referencias}

Álvarez Asián, Enrique (2011). "De Bergson a Deleuze: la ontología de la imagen cinematográfica", Eikasia 41, 93-111.

Corazón, Rafael, 1996. "Presupuestos de la Noción de Creación Continuada. Existencia y Tiempo en Descartes". Thémata. Revista de Filosofía $16,65-84$.

Deleuze, Guilles (2011). Cine II: Los signos de movimiento y tiempo. Buenos Aires: Editorial Cactus.

Deleuze, Guilles (1994). La imagen-movimiento. Estudios sobre cine 1. Barcelona: Ediciones Paidós.

García Barrientos, José Luis (1991). Drama y tiempo. Madrid: Consejo Superior de Investigaciones Científicas.

García Gil, Fernando (2006). Imagen/imaginario. Interdisciplinariedad de la imagen artística. Granada: Universidad de Granada.

Iniciarte, Fernando; Flamarique, Lourdes (2004). Imágenes, Palabras, Signos. Sobre Arte y Filosofía. Pamplona: Eunsa.

Joule, Andy (2011). "La paradoja del tiempo en animación. Si lo inanimado también experimenta el tiempo real ¿Por qué parece vivo por un momento?" Con A de Animación 1, 55-62.

Lloret, Carmen (2016). "Moverse o no ser. El movimiento dibujado: síntesis-mímesis, dos visiones contrapuestas." En: VV AA. Dibujo como forma de conocimiento. Valencia: Sendemá.

Merleau-Ponty, Maurice (1997). Fenomenología de la percepción. Barcelona: Ediciones Península. 
Platón (1999). Timeo. Buenos Aires: Ediciones Colihue. (Traducción Conrado Eggers Lan).

Rubio Lapaz, Jesús (2010). "Tiempo simbólico y tiempo real en la producción estética moderna”, Hum 736: Papeles de Cultura Contemporánea 12, 49-62.

Alicia Fernández: Profesora Ayudante Doctora.

Contact Address: Facultad de Ciencias de la Educación. Universidad de Granada. Campus Universitario de Cartuja, s/n. Despacho 334-1. 18071 Granada. España

E-mail address: alilia@ugr.es 